\title{
A bioinspired dual-crosslinked tough silk protein hydrogel as a protective biocatalytic matrix for carbon sequestration
}

\author{
Chang Sup Kim ${ }^{1,4}$, Yun Jung Yang ${ }^{2,4}$, So Yeong Bahn ${ }^{3}$ and Hyung Joon Cha ${ }^{2,3}$
}

The development of carbonic anhydrase (CA)-based materials for the environment-friendly sequestration of carbon dioxide $\left(\mathrm{CO}_{2}\right)$ under mild conditions would be highly valuable for controlling emissions to the environment and for producing value-added chemicals. Here, a highly tough and stable CA-encapsulating silk protein hydrogel was developed as a robust biocatalyst for $\mathrm{CO}_{2}$ sequestration through a bioinspired dual-crosslinking strategy that employed photoinduced dityrosine chemical crosslinking followed by dehydration-mediated physical crosslinking. The target enzyme was efficiently encapsulated in the silk hydrogel with $\sim 60 \%$ retention of the activity of free $C A$, and the encapsulated CA exhibited excellent overall multi-use, storage and thermal stabilities. The dual-crosslinked CA-encapsulating silk hydrogel exhibited a significant compressive modulus, which surpassed the moduli of most traditional and double-network hydrogels as well as those of enzyme-encapsulated hydrogels. This hydrogel also showed high resiliency and elasticity and outstanding structural stability. Importantly, the dual-crosslinked CA-encapsulating silk hydrogel facilitated the sequestration of $\mathrm{CO}_{2}$ into calcium carbonate with high $\mathrm{CO}_{2}$ hydration activity. Thus, the unique combination of bioinspired dual-crosslinking with silk fibroin protein and $\mathrm{CA}$ enzyme demonstrates the successful application of this protein hydrogel as a promising biocatalyst for $\mathrm{CO}_{2}$ sequestration by showing high activity, strong mechanical properties and outstanding structural stability.

NPG Asia Materials (2017) 9, e391; doi:10.1038/am.2017.71; published online 30 June 2017

\section{INTRODUCTION}

Reducing the levels of the major greenhouse gas carbon dioxide $\left(\mathrm{CO}_{2}\right)$ under mild conditions is considered an important issue for a sustainable environment. Carbonic anhydrase (CA) is a zinc metalloenzyme that catalyzes the reversible hydration reaction of $\mathrm{CO}_{2}$, the rate-limiting step of carbonation, with a $k_{\text {cat }}$ value of up to $\sim 10^{6}$. ${ }^{1}$ Because of its outstanding ability to rapidly sequestrate $\mathrm{CO}_{2}$ in an environment-friendly manner, ${ }^{2} \mathrm{CA}$ is being studied for potential use to reduce $\mathrm{CO}_{2}$ levels. However, its low stability and poor reusability strongly limit its practical use. ${ }^{3}$ These problems have been partially ameliorated by immobilizing CA onto a variety of solid materials (for example, controlled pore glass, magnetic particles, and silica) and soft materials (for example, beads and membranes). ${ }^{4-11}$ Although the immobilized CAs exhibited improved reusability and enhanced thermostability, most of the methods required harsh conditions and long preparation periods, which generally results in a severe reduction in enzyme activity and low immobilization efficiency. Therefore, proper immobilization is considered as one of the key issues in the development of CA-based biocatalysts for $\mathrm{CO}_{2}$ sequestration.
Hydrogels have received significant attention owing to their successful applications in tissue engineering, ${ }^{12}$ drug delivery, ${ }^{13}$ biocatalysts, ${ }^{14-21}$ selective transport, ${ }^{22}$ and three-dimensional printing. ${ }^{23}$ Considering that $\mathrm{CA}$ catalyzes $\mathrm{CO}_{2}$ hydration in aqueous solution, ${ }^{1}$ hydrogels can be an appropriate support for CA encapsulation because they generally have high water content and effective mass transfer. ${ }^{24-26}$ In addition, they have a three-dimensional structure that can provide sufficient capacity to accommodate the enzyme. ${ }^{24,25}$ Several synthetic polymers have been employed to fabricate enzymeencapsulated hydrogels, and they have shown the possibility for use as a biocatalyst. ${ }^{15-18}$ However, they have some limitations, including the use of harsh conditions to prepare materials or to prevent enzyme leaching from the hydrogel by increasing their size and low compatibility with the enzyme, resulting in reduced enzyme activity and stability. ${ }^{16-18}$ Recently, researchers have become increasingly interested in the potential of natural polymers, such as proteins, peptides, carbohydrates and DNA, to function as immobilization supports owing to their excellent biological compatibility for enzymes. ${ }^{19-21}$ To date, only a few studies have reported the use of natural polymers

${ }^{1}$ School of Chemistry and Biochemistry, Yeungnam University, Gyeongsan, Republic of Korea; ${ }^{2}$ Department of Chemical Engineering, Pohang University of Science and Technology, Pohang, Republic of Korea and ${ }^{3}$ School of Interdisciplinary Bioscience and Bioengineering, Pohang University of Science and Technology, Pohang, Republic of Korea

${ }^{4}$ These authors contributed equally to this work.

Correspondence: Professor HJ Cha, Department of Chemical Engineering, Pohang University of Science and Technology, 77 Cheongam-Ro. Nam-Gu, Pohang 37673, Republic of Korea.

E-mail: hjcha@postech.ac.kr

Received 8 October 2016; revised 15 January 2017; accepted 13 March 2017 
in the preparation of hydrogels for enzyme encapsulation. ${ }^{19-21}$ Unfortunately, even though the natural polymer-based hydrogels could be good for preserving enzyme activity, they have usually exhibited weak mechanical properties, poor elasticity and low structural stability, which significantly limits their use as supports for enzymes. ${ }^{19-21}$ Thus, a prerequisite for the use of natural polymerbased hydrogels as catalytic materials is to significantly enhance their mechanical properties and structural stability while effectively retaining enzyme activity.

The use of structural proteins and the exploitation of their structures and interactions for mechanical properties and stability could be a promising approach capable of circumventing the limitations of natural polymer-based hydrogels as supports for enzymes. Silk fibroins are one of the major structural proteins in the formation of the cocoons that protect silkworms from various environmental stresses. ${ }^{27,28}$ Silk fibroins are an abundant and cheap matrix polymer. The ability of silk fibroin to stabilize functionally diverse enzymes has been highlighted. ${ }^{29-31}$ Bombyx mori silk fibroin has $\sim 5 \mathrm{~mol} \%$ of tyrosine (tyr) residues and contains natural dityrosine crosslinking that can generally contribute to the stability, elasticity and strength of some structural proteins such as resilins of dragonfly wings and locust cuticles. ${ }^{32-35}$ Enzyme-catalyzed dityrosine crosslinking strategies, such as the use of tyrosinase or horseradish peroxidase, have been shown to be effective at forming regenerated silk fibroinbased hydrogels with high elasticity. ${ }^{36,37}$ Although this method has positively contributed to the mechanical properties of silk hydrogel, it would present some limitations in the preparation of enzymeencapsulated silk hydrogel, including the requirement of extended preparation time and the encapsulation of other undesired enzymes. Recently, we demonstrated that photoinduced dityrosine crosslinking can form a hydrogel from a silk-like elastic protein within seconds and can confer high elasticity to the hydrogel. ${ }^{38}$ Considering that Neisseria gonorrhoeae CA (ngCA) in this study has $\sim 4 \mathrm{~mol} \%$ of tyr residues that are not related to the active site and that the photoinduced dityrosine crosslinking method has a rapid reaction rate under mild buffer conditions, ${ }^{38,39}$ this crosslinking strategy could be appropriate for the preparation of an elastic silk fibroin hydrogel with efficient ngCA encapsulation. In addition, silk fibroins consist of $\beta$-sheet crystallites with amorphous domains. ${ }^{28,33}$ The strong interactions between $\beta$-sheets contribute to the superior mechanical properties and structural stability of silk fibroin. ${ }^{40,41}$ The addition of $\beta$-sheets in the

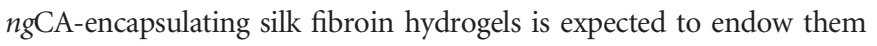
with high strength and structural stability while maintaining a considerable degree of elasticity. In addition, it has been reported that silk fibroin could regulate both the morphology and crystallographic polymorphs of $\mathrm{CaCO}_{3}$, a major product of $\mathrm{CO}_{2}$ sequestration, by CA-based mineral carbonation. ${ }^{42,43}$ Therefore, it is of interest to exploit these characteristics of silk fibroin for the preparation of a CA-encapsulating silk hydrogel as a robust biocatalyst for $\mathrm{CO}_{2}$ sequestration.

Herein, we report the fabrication of a highly tough and stable CA-encapsulating silk hydrogel (called dc-ngCA-silk hydrogel) by employing a bioinspired dual-crosslinking strategy, photoinduced dityrosine crosslinking followed by dehydration-mediated physical cross-linking ( $\beta$-sheet formation). To the best of our knowledge, this is the first study to apply a dual-crosslinking approach to fabricate highly tough and stable silk hydrogels and to develop hydrogels as biocatalysts for $\mathrm{CO}_{2}$ sequestration.

\section{MATERIALS AND METHODS}

\section{Preparation of $n g C A$}

The $n g C A$ enzyme was expressed and purified as previously reported. ${ }^{1}$ In brief, recombinant Escherichia coli containing an ngCA-expressing vector was grown to $0.6-0.8$ optical density at $600 \mathrm{~nm}\left(\mathrm{OD}_{600}\right)$ at $37^{\circ} \mathrm{C}$ in Luria-Bertani medium $(0.5 \%$ yeast extract, $1 \%$ tryptophan and $1 \% \mathrm{NaCl})$ with $50 \mu \mathrm{g} \mathrm{ml}^{-1}$ ampicillin (Sigma Aldrich, Milwaukee, WI, USA). Then, $1 \mathrm{~mm}$ isopropyl- $\beta$-D-thiogalactopyranoside (Sigma-Aldrich) and $0.1 \mathrm{~mm} \mathrm{ZnSO}_{4}$ (Sigma-Aldrich) were added to the culture medium to express $n g \mathrm{CA}$. The recombinant cells were grown for an additional $10 \mathrm{~h}$ at $37^{\circ} \mathrm{C}$. The cells were harvested by centrifugation at 4000 r.p. $\mathrm{m}$. for $10 \mathrm{~min}$. The cell pellet was resuspended in lysis buffer $\left(50 \mathrm{~mm} \mathrm{NaH} \mathrm{PO}_{4}\right.$, $300 \mathrm{~mm} \mathrm{NaCl}$ and $10 \mathrm{~mm}$ imidazole; $\mathrm{pH}$ 8.0) and disrupted with a sonic dismembrator (Sonics and Materials, Newton, CT, USA) for $10 \mathrm{~min}$ at $50 \%$ power ( $5 \mathrm{~s}$ pulse on and $2 \mathrm{~s}$ pulse off). The soluble fraction was collected by centrifugation at $10000 \mathrm{~g}$ at $4{ }^{\circ} \mathrm{C}$ for $30 \mathrm{~min}$. For purification, the soluble fraction was loaded into a Ni-NTA column (Qiagen, Hilden, Germany). The $n g C A$ was eluted with elution buffer $\left(50 \mathrm{~mm} \mathrm{NaH}{ }_{2} \mathrm{PO}_{4}, 300 \mathrm{~mm} \mathrm{NaCl}\right.$, and $250 \mathrm{~mm}$ imidazole; $\mathrm{pH}$ 8.0). The eluted fraction was dialyzed against $20 \mathrm{~mm}$ Tris- $\mathrm{SO}_{4}(\mathrm{pH}$ 8.3). The protein concentration was determined by a Bradford assay (Bio-Rad, Hercules, CA, USA) using bovine serum albumin (SigmaAldrich) as a standard.

\section{Fabrication of the dc-ngCA-silk hydrogel}

The dc-ngCA-silk hydrogel was prepared by using a dual-crosslinking strategy, specifically, photochemical dityrosine crosslinking and dehydration-mediated physical crosslinking. ${ }^{38,44}$ Silk fibroin (provided from Dr KH Lee at Seoul National University, Korea) was dissolved in a $n g \mathrm{CA}$ solution $(20 \mathrm{~mm}$ Tris-HCl; $\mathrm{pH}$ 8.3), which was stirred for $1 \mathrm{~h}$. Tris(bipyridine)ruthenium(II) chloride $\left(\left[\mathrm{Ru}(\mathrm{bpy})_{3}\right]^{+}{ }^{2}\right.$ Sigma-Aldrich) and sodium persulfate (Sigma-Aldrich) were added to the solution with final concentrations of $1 \mathrm{~mm}$ and $50 \mathrm{~mm}$, respectively, and then mixed with stirring until the solution reached a uniform phase. For gelation, the solution was exposed to visible light $(\sim 450 \mathrm{~nm})$ for $60 \mathrm{~s}$. The hydrogel was additionally treated with $90 \%(\mathrm{v} / \mathrm{v})$ methanol for $60 \mathrm{~min}$ and then washed with a large amount of $20 \mathrm{~mm}$ Tris-SO $\mathrm{SO}_{4}(\mathrm{pH}$ 8.3) to remove any remaining methanol in the hydrogel.

\section{High-performance liquid chromatography analysis}

The ratio of dityrosine to tyr in the fabricated dc-ngCA-silk hydrogel was quantitatively evaluated via high-performance liquid chromatography analysis of its acid hydrolysate. ${ }^{34} \mathrm{~A}$ sample of the dc-ngCA-silk hydrogel was added to $500 \mu \mathrm{l}$ of $6 \mathrm{~N} \mathrm{HCl}$ containing $0.1 \%$ phenol. After oxygen was removed using argon gas, acid hydrolysis was conducted at $145^{\circ} \mathrm{C}$ for $4 \mathrm{~h}$. The acid hydrolysate was then diluted to $5 \mathrm{ml}$ with mobile phase buffer $(8 \%(\mathrm{v} / \mathrm{v})$ acetonitrile and $0.1 \%(\mathrm{v} / \mathrm{v})$ trifluoroacetic acid), followed by centrifugation at 14000 r.p.m. for $15 \mathrm{~min}$. After evaporation to dryness, the sample was reconstituted with $100 \mu \mathrm{l}$ of water and transferred to an high-performance liquid chromatography vial for analysis. Then, dityrosine analysis was performed using a Bio LC system (Thermo Fisher Scientific, Waltham, MA, USA) comprising a C18 column (OD-300, $250 \times 4.6 \mathrm{~mm}$; PerkinElmer (Waltham, MA, USA)) and a UV-Vis detector. A sample of uncrosslinked silk fibroin and $n g \mathrm{CA}$ was used as a negative control. A standard curve was obtained using dityrosine (Carbosynth, Compton, Bershire, UK) and tyr (Sigma-Aldrich) standards.

\section{Fourier transform infrared spectroscopy analysis}

FTIR spectra were measured with a Bruker Vretex-80V fourier transform infrared spectroscopy (FTIR) spectrometer (Bruker Optik GmbH, Karlsruhe, Baden-Württemberg, Germany) equipped with a deuterated triglycine sulfate detector and a multiple-reflection, horizontal MIRacle ATR attachment (using a Ge crystal from Pike tech (Madison, WI, USA). The absorption spectra were collected between $400 \mathrm{~cm}^{-1}$ and $4000 \mathrm{~cm}^{-1}$. The absorbances of the samples and background were measured using 128 scans at a resolution of $4 \mathrm{~cm}^{-1}$.

\section{Swelling property analysis}

Lyophilized dc-ngCA-silk hydrogels were immersed in $20 \mathrm{~mm}$ Tris- $\mathrm{HCl}$ (pH 8.3) for 1 day. The weights of the swollen silk hydrogels were measured 
after the removal of excess water. For each specimen, three independent tests were conducted. The water amount, swelling ratio and fluid recovery were calculated as follows: water amount $(\mathrm{mg})=\left(W_{\mathrm{g}}-W_{\mathrm{d}}\right)$, swelling ratio $=\left(W_{\mathrm{t}}-W_{\mathrm{d}}\right) / W_{\mathrm{d}}$, and fluid recovery $(\%)=\left(W_{\mathrm{t}}-W_{\mathrm{d}}\right) /\left(W_{\mathrm{g}}-W_{\mathrm{d}}\right) \times 100$, where $W_{\mathrm{t}}$ is the weight $(\mathrm{mg})$ of the swollen hydrogel at time $t, W_{\mathrm{d}}$ is the weight $(\mathrm{mg})$ of the dried silk hydrogel and $W_{\mathrm{g}}$ is the weight $(\mathrm{mg})$ of the hydrogel before drying.

\section{Morphology analysis}

dc-ngCA-silk hydrogel was frozen at $-80^{\circ} \mathrm{C}$ and fractured using liquid nitrogen before freeze-drying. The morphology of the freeze-dried sample was observed by FE-SEM (field emission-scanning electron microscopy; XL30S FEG; Philips, Netherlands) at an accelerating voltage of $5 \mathrm{kV}$ with platinum coating.

\section{Mechanical property analysis}

Unconfined compression tests of the dc-ngCA-silk hydrogel $(8 \mathrm{~mm}$ diameter $\times 2 \mathrm{~mm}$ height) were performed by using an Instron 3344 materials testing system (Instron, Wycombe, Buckinghamshire, UK) equipped with a $2 \mathrm{kN}$ load cell. The samples were compressed at a rate of $1 \mathrm{~mm} \mathrm{~min}^{-1}$ until a maximum strain of $\sim 50 \%$ was reached $(n=3)$. The stress-strain curves were obtained, and the compressive tangent moduli were calculated at 20\% and $40 \%$ strains. The hydrogel was also subjected to 20 loading-unloading cycles at $20 \%$ strain. The 20 cycles were recorded, and the energy dissipation was calculated as follows:

$$
\text { Energy dissipation }=\int_{\text {loading }} \sigma_{\text {comp }} d \varepsilon-\int_{\text {unloading }} \sigma_{\text {comp }} d \varepsilon
$$

\section{Enzyme activity analysis}

The activity of the hydrogel was evaluated using a well-established esterase assay, which involved hydrolysis of $p$-nitophenyl acetate ( $p$-NPA;
Sigma-Aldrich) to $p$-nitrophenol and acetate. $p$-nitrophenol was detected by measuring the absorbance at the $\lambda_{\max }$ of $348 \mathrm{~nm}$ using UV-vis spectroscopy (Shimazu, Japan). ${ }^{45}$ Then, a $30 \mathrm{~mm} p$-NPA solution was prepared by dissolving the appropriate mass in $100 \%(\mathrm{v} / \mathrm{v})$ acetonitrile. The assay was performed with gentle stirring at $25^{\circ} \mathrm{C}$ in a $1 \mathrm{ml}$ total reaction volume, which consisted of $900 \mu \mathrm{l}$ of $20 \mathrm{~mm}$ potassium phosphate ( $\mathrm{pH} 7.0$ ), $100 \mu \mathrm{l}$ of a $30 \mathrm{~mm}$ p-NPA solution (final concentration of $3 \mathrm{~mm}$ ), and the ngCA-encapsulating silk hydrogel. The absorbance was measured at $348 \mathrm{~nm}$ after incubation for $12 \mathrm{~min}$. Note that the enzyme activity assay method was used to evaluate the $n g C A$-immobilizing capacity of the hydrogel, the effect of methanol on the activity of the encapsulated $n g C A$, and the multi-use stability, thermal stability and storage stability.

\section{Evaluation of multi-use, thermal and storage stabilities}

The reusability of the dc-ngCA-silk hydrogel was evaluated by using an enzyme activity assay method. The by-product in the hydrogel was eliminated by dialyzing against $20 \mathrm{~mm}$ Tris- $\mathrm{SO}_{4}$ buffer $(\mathrm{pH}$ 8.3) for additional uses. To investigate its thermal stability, the hydrogel was stored at $4{ }^{\circ} \mathrm{C}$ prior to use. dc-ngCA-silk hydrogel was incubated in a closed bottle containing a sufficient volume of $20 \mathrm{~mm}$ Tris-SO $\mathrm{SO}_{4}$ buffer $(\mathrm{pH} 8.3)$ at $50{ }^{\circ} \mathrm{C}$ for $1 \mathrm{~h}$ or $12 \mathrm{~h}$ and then stored at $4{ }^{\circ} \mathrm{C}$ until the enzyme activities were measured. To investigate its storage stability, dc-ngCA-silk hydrogel was stored in a closed bottle containing a sufficient volume of $20 \mathrm{~mm}$ Tris- $\mathrm{SO}_{4}$ buffer $(\mathrm{pH} 8.3)$ at $30{ }^{\circ} \mathrm{C}$ and tested at intervals of $\sim 7$ days.

$\mathrm{CO}_{2}$ sequestration ability analysis

The effects of dc-ngCA-silk hydrogel on the sequestration of $\mathrm{CO}_{2}$ into $\mathrm{CaCO}_{3}$ were evaluated by measuring a mass of precipitated $\mathrm{CaCO}_{3} \cdot \mathrm{CO}_{2}$-saturated water was prepared by bubbling $\mathrm{CO}_{2}$ in water at $18{ }^{\circ} \mathrm{C}$ in an open system. ${ }^{4}$ Five milliliters of $\mathrm{CO}_{2}$-saturated water was added to $5 \mathrm{ml}$ of reaction buffer (1 M Tris- $\mathrm{SO}_{4}$ and $20 \mathrm{mM} \mathrm{CaCl}_{2} ; \mathrm{pH} 9.5$ ) containing the hydrogel. The reaction

a

\section{Bioinspired photo-induced chemical crosslinking}

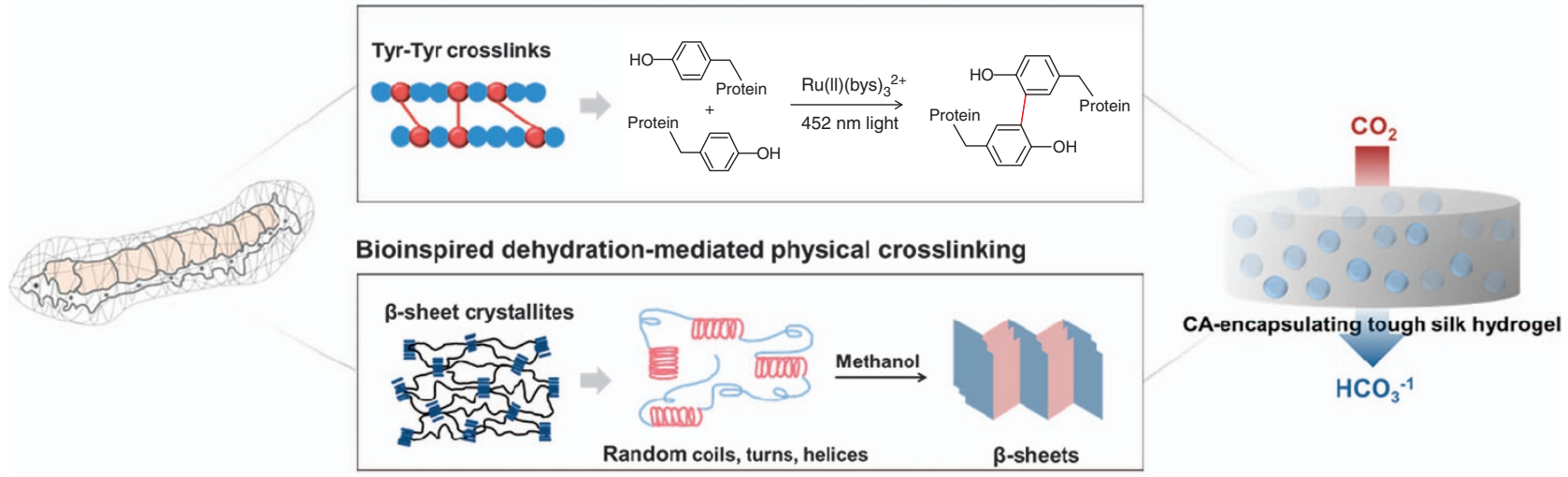

b

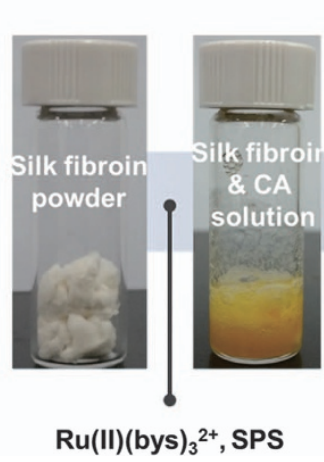

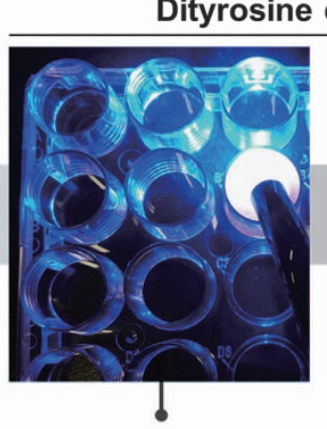

Blue light exposure $\beta$-sheets formation

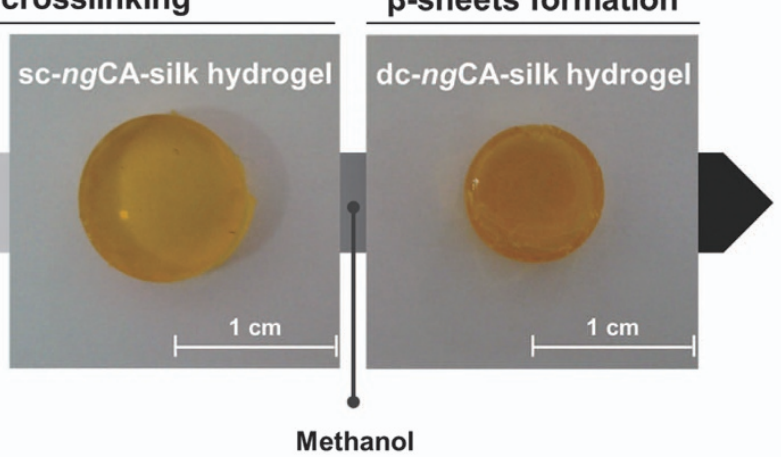

Figure 1 (a) Schematic illustration of the preparation of the highly tough and stable CA-encapsulating silk hydrogel as a robust biocatalyst for $\mathrm{CO}_{2}$ sequestration. (b) Fabrication of the dc-ngCA-silk hydrogel through bioinspired photoinduced chemical and dehydration-mediated physical dual-crosslinking. 
was performed at ambient temperature in a closed system for $150 \mathrm{~s}$. The final product was filtered through a $0.1 \mu \mathrm{m}$-pore-membrane filter and then dried at $85{ }^{\circ} \mathrm{C}$ overnight. The precipitated $\mathrm{CaCO}_{3}$ was weighed. The mass of $\mathrm{CO}_{2}$ removed was estimated based on the mass of $\mathrm{CaCO}_{3}$. Because the solubility of $\mathrm{CO}_{2}$ in water at $18{ }^{\circ} \mathrm{C}$ is $1.8 \mathrm{~g} \mathrm{~kg}^{-1}$-water and $5 \mathrm{ml}$ of $\mathrm{CO}_{2}$-saturated water was used, the amount of $\mathrm{CO}_{2}$ used was $9 \mathrm{mg}$. The $\mathrm{CO}_{2}$-removal efficiency can be calculated as follow: $\mathrm{CO}_{2}$-removal efficiency $(\%)=$ (the mass of removed $\left.\mathrm{CO}_{2} / 9\right) \times 100$. In addition, the morphology and polymorphs of the $\mathrm{CaCO}_{3}$ were analyzed by FE-SEM and X-ray powder diffraction (Rigaku, Japan) as previously described. ${ }^{46}$

\section{In vitro $\mathrm{CaCO}_{3}$ crystallization}

The effect of dc-ngCA-silk hydrogel on in vitro $\mathrm{CaCO}_{3}$ crystallization was investigated by exploiting the slow diffusion of ammonium carbonate vapor in calcium chloride solution as previously described. ${ }^{46}$ The morphology of the precipitated $\mathrm{CaCO}_{3}$ was analyzed by FE-SEM.

\section{RESULTS AND DISCUSSION}

Formation and characterization of the dc-ngCA-Silk hydrogel The fabrication procedure of the tough and stable CA-encapsulating silk hydrogel as a robust biocatalyst for $\mathrm{CO}_{2}$ sequestration is illustrated in Figure 1. For easy handling and to enhance their mechanical properties while minimizing diffusion limitations, the dc-ngCA-silk hydrogels were fabricated as macroscopically well-defined particles with a diameter of $\sim 8 \mathrm{~mm}$ and a thickness of $\sim 2 \mathrm{~mm}$. First, the
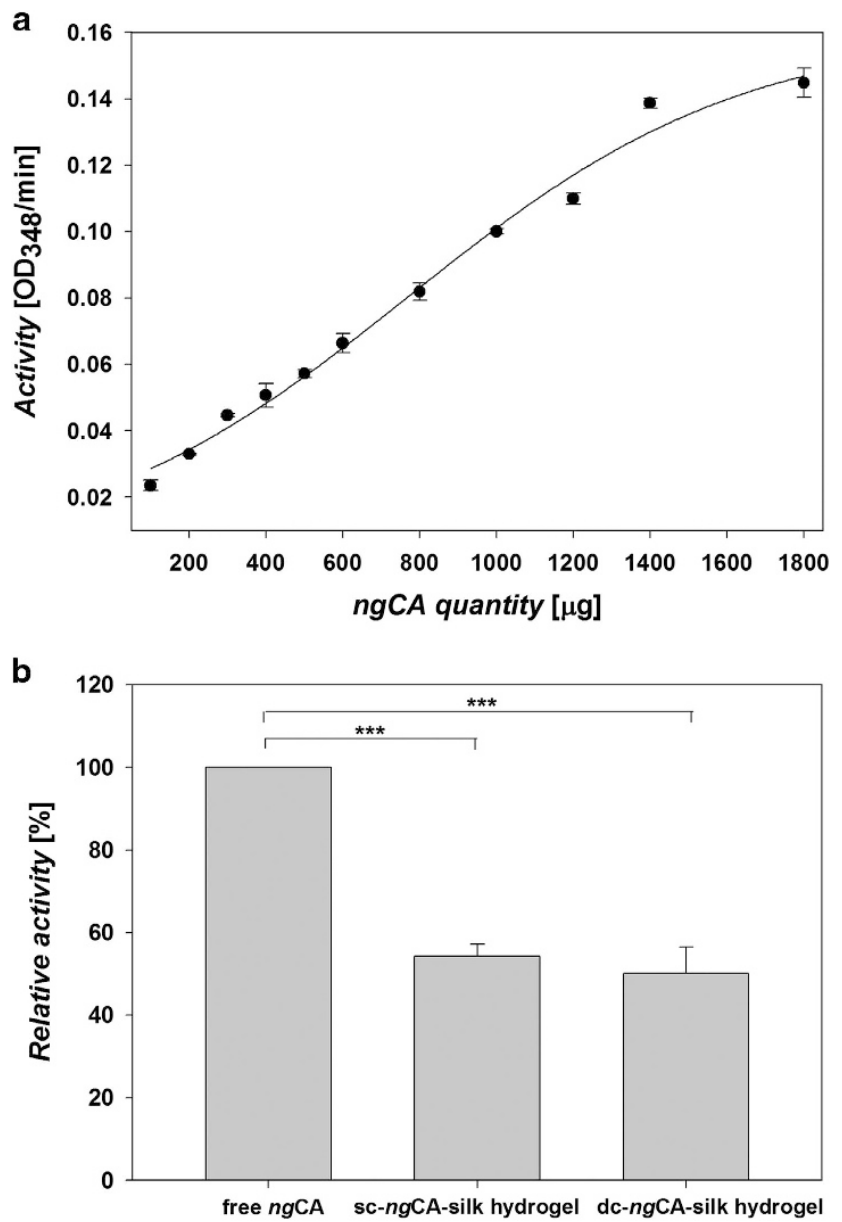

Figure 2 (a) ngCA-encapsulating capacity of the dual-crosslinked silk hydrogel. (b) Residual enzyme activity after encapsulating ngCA within the silk hydrogel $\left({ }^{* *} \mathrm{P}<0.005\right.$; unpaired $t$-test). The activity was assayed by p-NPA hydrolysis. amount of $n g$ CA capable of being encapsulated in a silk hydrogel via photochemical dityrosine crosslinking was investigated by measuring the $p$-NPA hydrolysis activity of the hydrogel (Figure 2a). This approach was used because $\alpha$-type CA enzymes, such as ngCA, have both $p$-NPA hydrolysis and $\mathrm{CO}_{2}$ hydration activity. ${ }^{47}$ The $p$-NPA hydrolysis activity of $n g C A$ linearly increased according to its quantity $(100-1400 \mu \mathrm{g})$ with a high coefficient of determination $\left(R^{2}\right.$ of over 0.99 ) and almost reached saturation at a quantity $>1400 \mu \mathrm{g}$. This result indicated that up to $1800 \mu \mathrm{g}$ of $n g \mathrm{CA}$ could be encapsulated in the fabricated silk hydrogel through the photochemical dityrosine crosslinking method. In addition, we examined the extent of activity reduction by comparing the $p$-NPA hydrolysis activity of the $n g \mathrm{CA}$-encapsulating silk hydrogel through photochemical crosslinking (called sc-ngCA-silk hydrogel) with the activity of the free enzyme. We found that the sc-ngCA-silk hydrogel retained $\sim 54 \%$ of the activity of free $n g C A$ (Figure $2 b$ ). The reduced activity of the hydrogelencapsulated $n g \mathrm{CA}$ seemed to be due to the reduced flexibility of the encapsulated ngCA compared with that of the free enzyme. ${ }^{48,49}$ We also investigated the activity of encapsulated $n g C A$ after treating the sc-ngCA-silk hydrogel with methanol. The dc-ngCA-silk hydrogel exhibited $92 \%$ of the activity of the sc-ngCA-silk hydrogel, which corresponded to $\sim 50 \%$ of the activity of free $n g C A$ (Figure $2 b$ ). The high activity retention from the methanol treatment may be attributed to the high rigidity of the $n g C A$ encapsulated within the silk hydrogel through photochemical dityrosine crosslinking. ${ }^{48,49}$ The high activity retention of the dc-ngCA-silk hydrogel was comparable to that of CAs encapsulated in bioinspired silica ${ }^{4,5}$ and surpassed the activities of CAs immobilized in a biomineralized calcium carbonate crystalline composite $(\sim 43 \%)^{10}$ and glass $(\sim 38 \%){ }^{11}$

The presence of dityrosine crosslinks in the dc-ngCA-silk hydrogel was confirmed by their characteristic blue fluorescence under UV illumination (Figure 3a). Biomaterials containing dityrosine crosslinks have an excitation wavelength of $315 \mathrm{~nm}$ and an emission wavelength of $400 \mathrm{~nm} .{ }^{50}$ Agarose gel was used as a negative control because agarose can be easily formed into a gel through physical crosslinking. The dc-ngCA-silk hydrogel showed a distinct blue fluorescence (Figure 3a, top right image), whereas the control gel did not (Figure 3a, bottom right image). We also quantitatively evaluated the dityrosine crosslinking degree in the dc-ngCA-silk hydrogel via reverse-phase high-performance liquid chromatography analysis of its acid hydrolysate (Supplementary Figure S1). We found that the extent of dityrosine formation in the dc-ngCA-silk hydrogel was $\sim 50 \%$ (relative to the totaltyr residues). The formation of $\beta$-sheets in the dc-ngCA-silk hydrogel was supported by comparing the secondary structures of the sc-ngCA-silk hydrogel through FTIR analysis (Figure 3b). After methanol treatment, the silk hydrogel exhibited a large increase in the $\beta$-pleated-sheet crystal content that corresponded to the central absorption band at $\sim 1630 \mathrm{~cm}^{-1}$ in the FTIR spectra. ${ }^{51}$

The swelling properties of the dc-ngCA-silk hydrogel were monitored by incubating the lyophilized hydrogel. Before freezedrying, the dc-ngCA-hydrogel contained $92.20 \pm 0.24 \mathrm{mg}$ of water, which was almost half that $(187.43 \pm 2.08 \mathrm{mg})$ of the sc- $n g \mathrm{CA}$ hydrogel (Supplementary Figure S2). The hydrogel exhibited moderate swelling properties with a swelling ratio of 1.2 and a fluid recovery of $24.7 \%$ (Figure $4 \mathrm{a}$ ). These values were lower than those of other silk hydrogels with similar silk fibroin contents ${ }^{52}$ and sc-ngCA-silk hydrogel (Supplementary Table S1). These low values may be due to the formation of $\beta$-sheets during the methanol treatment. ${ }^{53}$ However, the swelling properties seemed to be unrelated to enzyme activity in the dc-ngCA-silk hydrogel. In addition, the morphology of the dc-ngCA-silk hydrogel was analyzed using FE-SEM (Figure 4b). 
The dc-ngCA-silk hydrogel showed a microporous and compact structure with an $\sim 50 \mu \mathrm{m}$-pore size.

\section{Mechanical properties of the dc-ngCA-Silk hydrogel}

The mechanical properties of the dc-ngCA-silk hydrogel were determined (Figure 5). The dc-ngCA-silk hydrogel exhibited high flexibility and elasticity (Figure 5a and Supplementary Movie S1). The dc-ngCA-silk hydrogel with an $8 \mathrm{~mm}$ diameter and a $2 \mathrm{~mm}$ height was able to sustain large loads without obvious deformation (Figure 5b for $100 \mathrm{~g}$ weight and Supplementary Figure S3 for $2 \mathrm{~kg}$ weight), indicating that the hydrogel was very tough and strong. In addition, an unconfined compression test was performed. The dc-ngCA-silk hydrogel exhibited complete recovery after removal (Figure $5 \mathrm{c}$ and Supplementary Movie S2) and did not fracture at up to 50\% strain with a compressive strength of $\sim 3 \mathrm{MPa}$ (Figure $5 \mathrm{~d}$ ). The compressive modulus of the dc-ngCA-silk hydrogel was determined as a tangent of the stress-strain curves at $20 \%$ and $40 \%$ strains. The dc-ngCA-silk hydrogel exhibited compressive moduli of $\sim 1.3 \mathrm{MPa}$ and $\sim 11 \mathrm{MPa}$ for $20 \%$ and $40 \%$ strain, respectively (Figure 5e), which surpassed the moduli of natural elastomers such as articular cartilage (0.3-0.8 MPa) and skin $(5.7 \mathrm{kPa})$ and was comparable to the modulus of bovine

\section{a}

w/o UV illumination
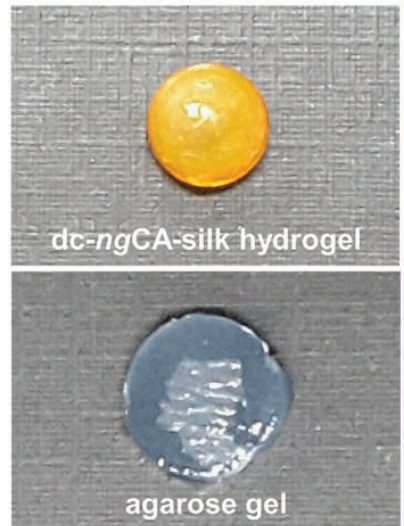

b

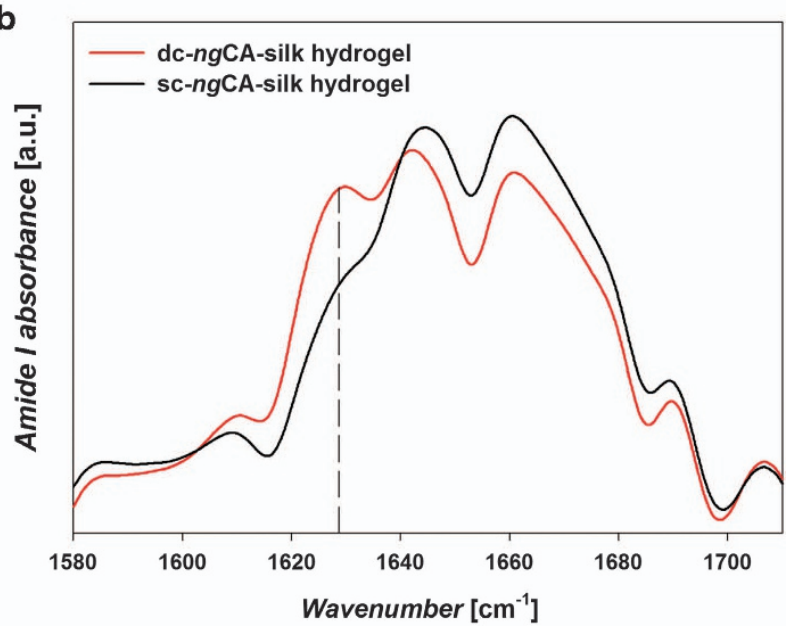

Figure 3 (a) Digital photographs of dc-ngCA-silk hydrogel (top) and agarose gel (bottom) under room light (left) and UV illumination (right). (b) FTIR absorbance spectra in the amide I region versus wavenumber for the dc-ngCA-silk and sc-ngCA-silk hydrogels. The medium-medium line marks the center of the absorbance band at $1630 \mathrm{~cm}^{-1}$ that corresponds to $\beta$-sheets.

\section{dc-ngCA-silk hydrogel}

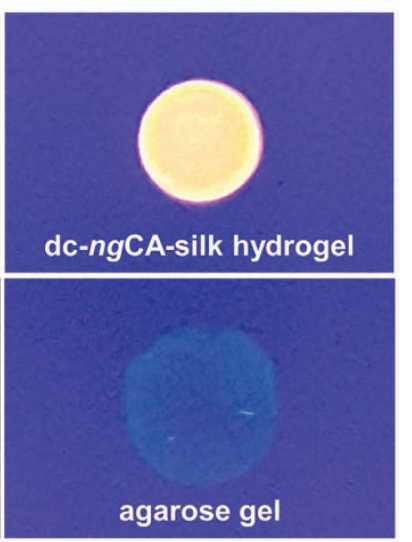

periodontal ligaments (4-8 MPa) ${ }^{54-56}$ The mechanical properties were notable compared with those of other enzyme-encapsulated hydrogels (Table 1). Peptide and poly(ethylene glycol) methacrylate-based hydrogels exhibited a compressive modulus of $\sim 7 \mathrm{kPa}$ at $80 \%$ strain, and a synthetic polymer-based hydrogel, which consisted of Fmoc-TyrOH, N,N-dimethylacrylamide and $\mathrm{N}$-hydroxyphthalimide, showed a compressive modulus of $\sim 207 \mathrm{kPa}$ at $20 \%$ strain. ${ }^{17,20}$ In addition, the mechanical properties of the dc-ngCA-silk hydrogel were much better than those of most traditional hydrogels (compressive modulus of $0.01-1 \mathrm{MPa}$ ) and of most double-network hydrogels $(0.1-1 \mathrm{MPa})$ that used the same solid content of $10 \%(\mathrm{w} / \mathrm{v}) .{ }^{57-59}$ The $\beta$-sheets especially contributed to the mechanical strength of the dc-ngCA-silk hydrogel, which was clearly supported compared to sc-ngCA-silk hydrogel (Supplementary Figure S4) and previous reports. ${ }^{40,41}$ We also investigated the reversible behavior of the dc-ngCA-silk hydrogel under cyclic compression (Figures $5 \mathrm{f}$ and g). The area of the hysteresis loop of the dc-ngCA-silk hydrogel markedly decreased during an initial five sequential cycles but almost reached a steady state with an energy dissipation of $\sim 5 \mathrm{~kJ} \mathrm{~m}^{-3}$ while compression strength remained nearly constant, which indicated that the hydrogel did not fracture under this condition. The decrease seemed to be the result of water escaping from the gel during the initial compression loading. It has been reported that water has a healing effect on hydrogels under cyclic compression. ${ }^{60}$ Because the dc-ngCAsilk hydrogel had a relatively low water level (Supplementary Figures S2 and 4a), the hydrogel might be affected by only a small amount of water being squeezed out of the gel during the initial cycles. However, the healing effects of water on the dc-ngCA-silk hydrogel might be more effective in aqueous environments. Collectively, these

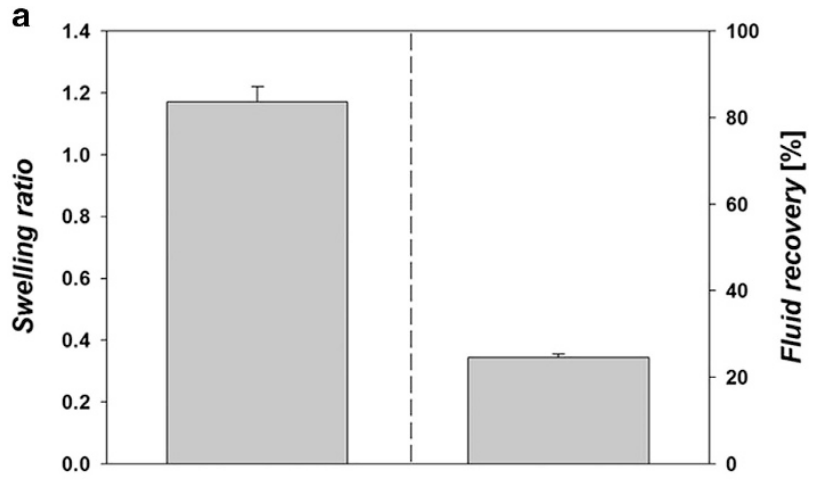

b

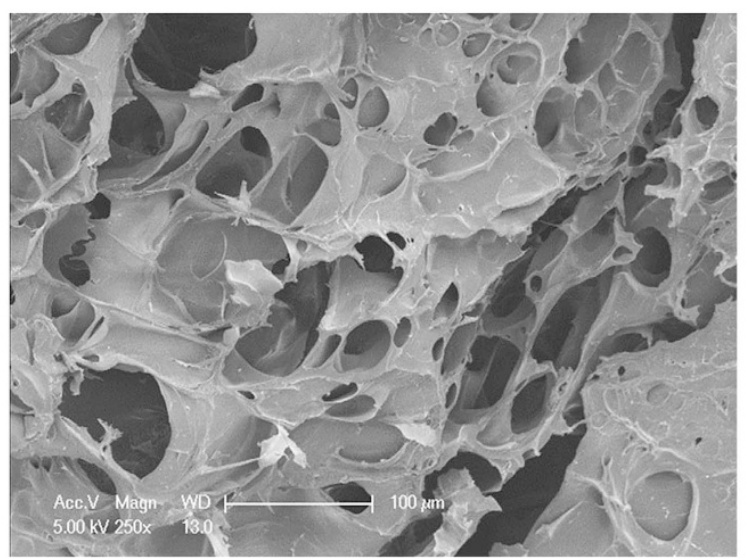

Figure 4 (a) Swelling properties of the dc-ngCA-silk hydrogel. (b) SEM images of a cross-section of the dc-ngCA-silk hydrogel. 
a

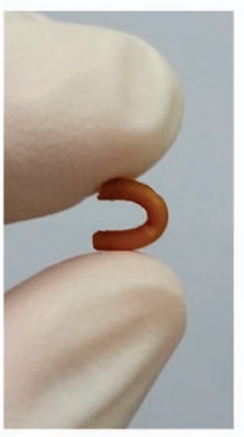

d

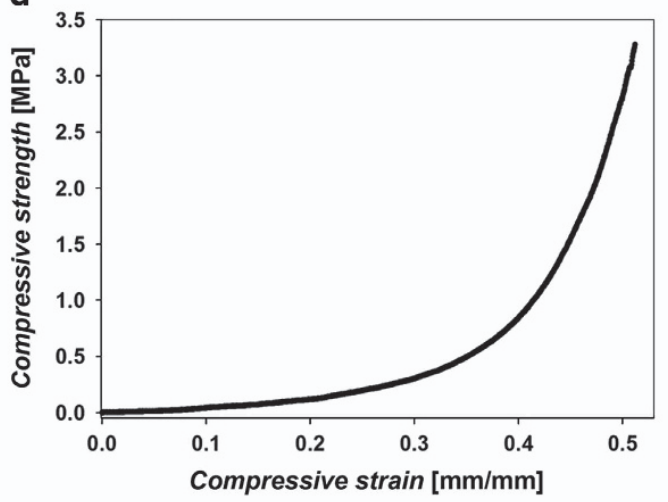

b

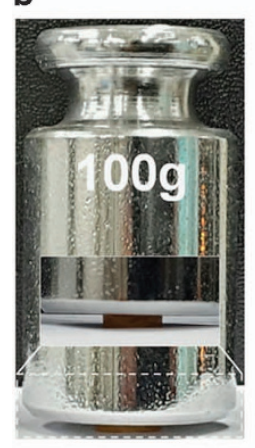

e

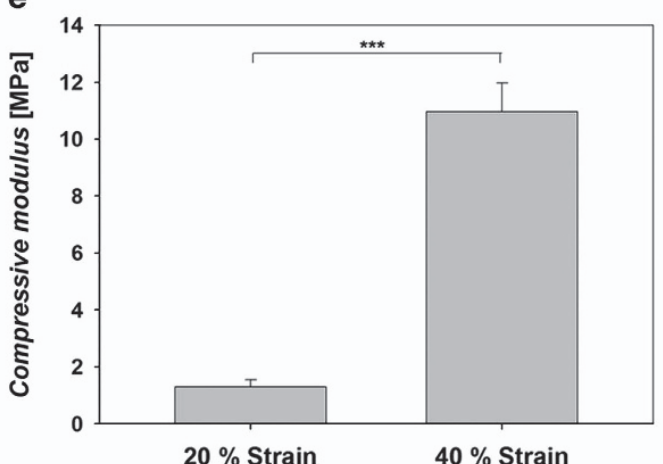

f

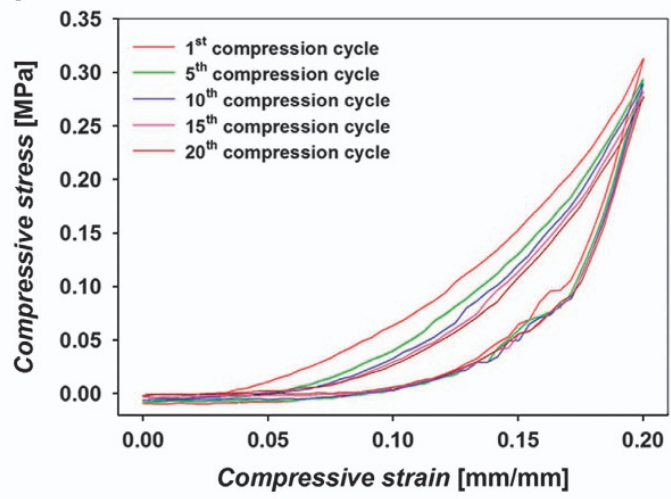

g

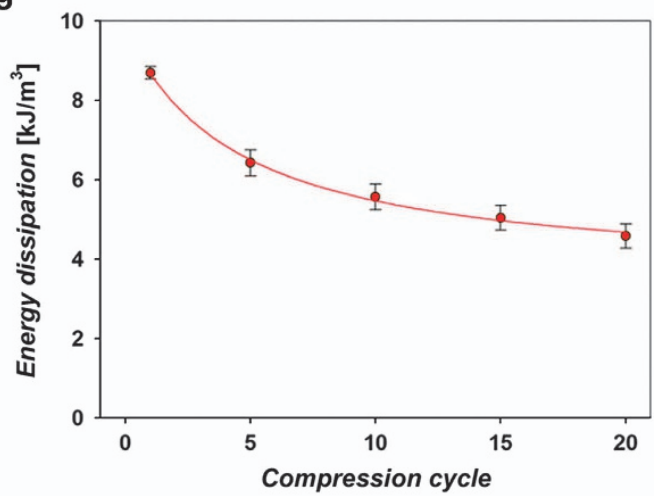

c
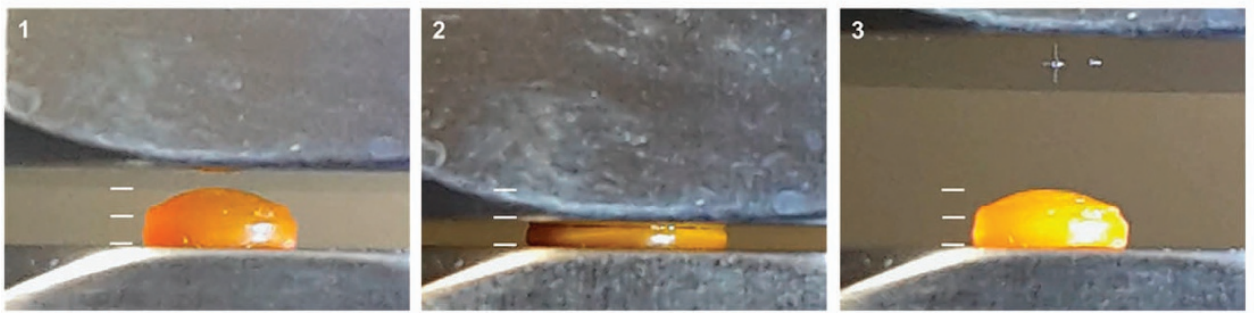

Figure 5 Mechanical properties of the dc-ngCA-silk hydrogel. Digital photograph of the hydrogel response to (a) bending and (b) compression forces. (c) Digital photograph of the hydrogel undergoing $\sim 60 \%$ compression. The hydrogel showed almost complete recovery after removal. (d) Representative compressive stress-strain curve of the hydrogel and (e) summarized compressive modulus as a function of compressive strain (*** $P<0.005$; unpaired $t$-test). (f) Representative cyclic loading-unloading curves of the hydrogel for 20 consecutive cycles. (g) The decay of energy dissipation for the hydrogel with increasing compressive cycle numbers.

Table 1 Mechanical properties of enzyme-encapsulating hydrogels

\begin{tabular}{|c|c|c|c|c|}
\hline Supporting material & Enzyme & Testing method & Mechanical performance & Reference \\
\hline \multicolumn{5}{|l|}{ Synthetic polymer } \\
\hline Fmoc-TyrOH, $\mathrm{N}, \mathrm{N}$-dimethylacrylamide, and $\mathrm{N}$-hydroxy-phthalimide & Glucose oxidase & Compression test & $\sim 206 \mathrm{kPa}$ at $20 \%$ strain $^{\mathrm{a}}$ & 17 \\
\hline Polyethyleneimine & Penicillin G acrylase & Compression test & $3.9-16.8 \mathrm{kPa}$ & 18 \\
\hline \multicolumn{5}{|l|}{ Natural peptides blended with synthetic polymers } \\
\hline Nap-Phe-Phe-Lys-acrylic acid and poly(ethylene glycol) methacrylate & $\begin{array}{l}\text { Glucose oxidase } \\
\text { Horseradish peroxidase }\end{array}$ & Compression test & $7 \mathrm{kPa}$ at $80 \%$ strain $^{\mathrm{a}}$ & 20 \\
\hline \multicolumn{5}{|l|}{ Natural polymer } \\
\hline Nap-Gly-Phe-Phe-pTyr, Nap-Gly-Phe-Phe-Tyr-Glu-ss-Glu-Gly, and alginate & $\begin{array}{l}\text { Phosphatase } \\
\text { Lactase }\end{array}$ & Rheology test & $12.3-22.2 \mathrm{kPa}^{\mathrm{b}}$ & 19 \\
\hline Alginate & $\begin{array}{l}\text { Phosphatase } \\
\text { Lactase }\end{array}$ & Rheology test & $12.1 \mathrm{kPa}$ & 19 \\
\hline Silk fibroin & Carbonic anhydrase & Compression test & $11 \mathrm{MPa}$ at $40 \%$ strain $^{\mathrm{a}}$ & This work \\
\hline
\end{tabular}

aMechanical performance was expressed as compressive modulus.

bMechanical performance was expressed as compressive strength when fracture of the hydrogel occurred. 

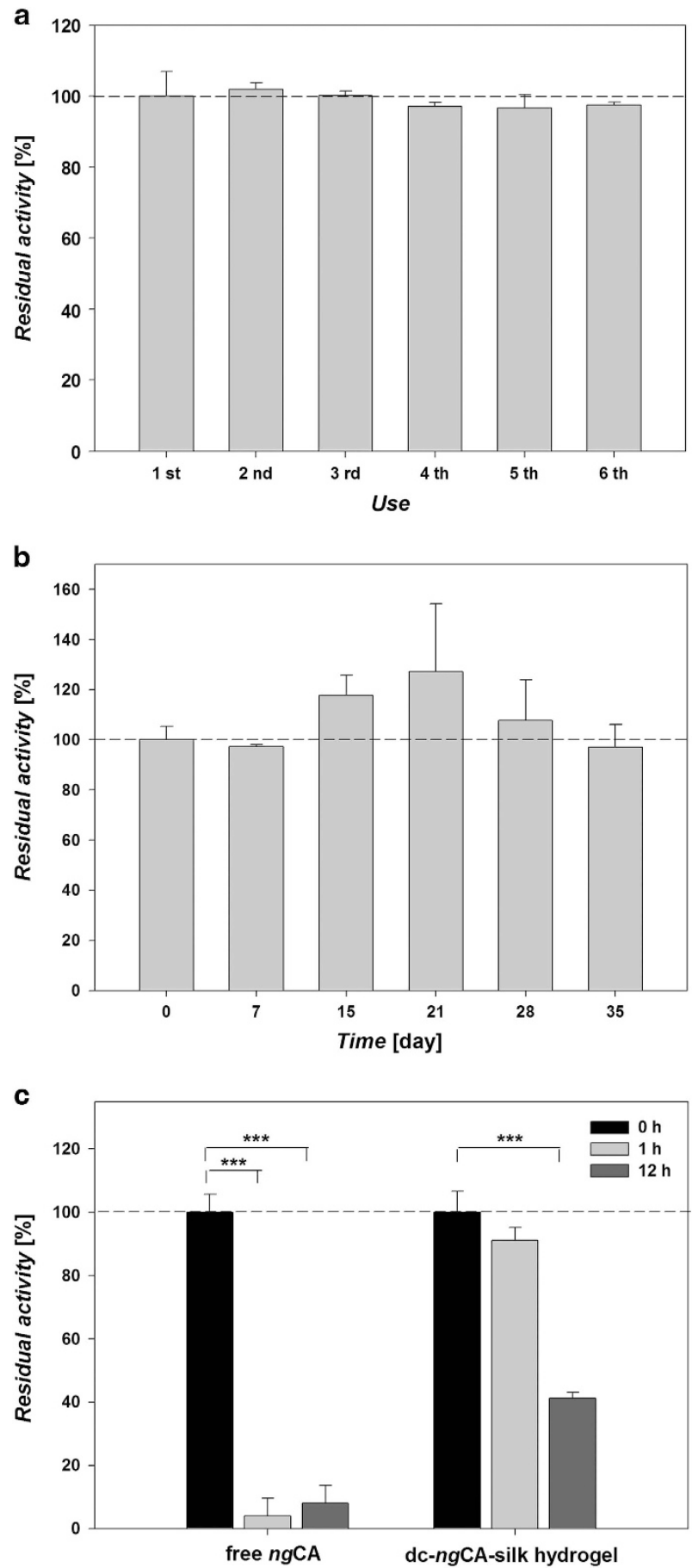

Figure 6 Stabilities of the dc-ngCA-silk hydrogel. (a) Multi-use stability, (b) storage stability at $30^{\circ} \mathrm{C}$, and (c) thermal stability at $50^{\circ} \mathrm{C}$. To assess its stability, $p$-NPA hydrolysis activity assays were performed at $25^{\circ} \mathrm{C}$ $\left({ }^{*} P<0.05,{ }^{*} P<0.01,{ }^{* * *} P<0.005\right.$; unpaired $t$-test).

results indicate that the dc-ngCA-silk hydrogel has high resilience and outstanding toughness, which seem to be due to the double-networkbased strong mechanical properties of silk fibroin.

Multi-use, storage and thermal stability of the dc-ngCA-Silk hydrogel

For practical applications of enzymes, an improvement of enzyme stability is one of the most important factors. Thus, the multi-use,
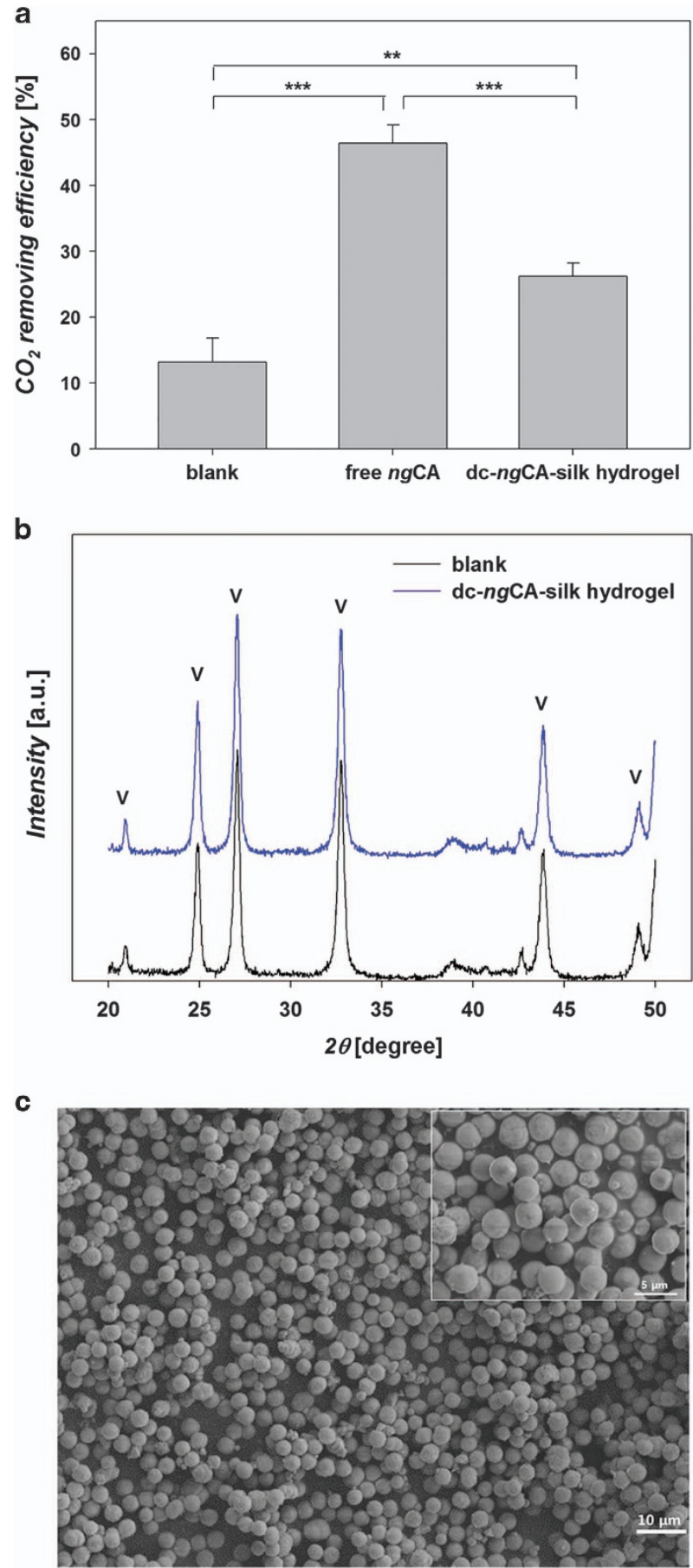

Figure 7 Sequestration of $\mathrm{CO}_{2}$ into $\mathrm{CaCO}_{3}$ by the dc-ngCA-silk hydrogel. (a) $\mathrm{CO}_{2}$-removal efficiency of the dc-ngCA-silk hydrogel $\left({ }^{* *} P<0.01\right.$, $* * * P<0.005$; unpaired $t$-test). (b) XRD and (c) SEM analyses of the $\mathrm{CaCO}_{3}$ precipitated by the dc-ngCA-silk hydrogel. V, vaterite.

storage and thermal stabilities of the dc-ngCA-silk hydrogel were assessed by measuring residual $p$-NPA hydrolysis activity. First, the multi-use stability was evaluated by examining the residual activity of the dc-ngCA-silk hydrogel after repeated use (Figure 6a). We found that the dc-ngCA-silk hydrogel retained $\sim 97 \%$ of its initial activity after the sixth use. This multi-use stability was higher than those of other supports for CA, including chitosan beads ( $43 \%)$, amine-based silica $(\sim 87 \%)$ and R5 peptide-based silica $(\sim 87 \%)$, whereas the 
Table 2 Sequestration of $\mathrm{CO}_{2}$ by the dc-ngCA-silk hydrogel in Figure $7 a$.

\begin{tabular}{lccc}
\hline & $\begin{array}{c}\text { Mass of precipitated } \\
\mathrm{CaCO}_{3}(\mathrm{mg})\end{array}$ & $\begin{array}{c}\text { Mass of removed } \\
\mathrm{CO}_{2}{ }^{\mathrm{c}}(\mathrm{mg})\end{array}$ & $\begin{array}{c}\mathrm{CO}_{2} \text {-removal } \\
\text { efficiency }^{d}(\%)\end{array}$ \\
\hline Blank & $2.7 \pm 0.7$ & $1.2 \pm 0.3$ & $13.2 \pm 3.6$ \\
Free $n g \mathrm{CA}^{\mathrm{a}}$ & $9.5 \pm 0.6$ & $4.2 \pm 0.3$ & $46.4 \pm 2.8$ \\
dc- $n g \mathrm{CA}$-silk & $5.4 \pm 0.3$ & $2.4 \pm 0.1$ & $26.2 \pm 2.0$ \\
hydrogel $^{\mathrm{b}}$ & & & \\
\hline
\end{tabular}

${ }^{a}$ The quantity of free $n g C A$ used in this experiment was $\sim 1.8 \mathrm{mg}$, and therefore, the concentration of the enzyme in the total reaction $(10 \mathrm{ml})$ was $0.18 \mathrm{mg} \mathrm{ml}^{-1}$.

bThe amount of $n g C A$ encapsulated in the silk hydrogel was $~ 1.8 \mathrm{mg}$.

${ }^{\mathrm{C}}$ Because the solubility of $\mathrm{CO}_{2}$ in water at $18^{\circ} \mathrm{C}$ is $1.8 \mathrm{~g} \mathrm{~kg}^{-1}$-water, the amount of $\mathrm{CO}_{2}$ used

in this experiment $(5 \mathrm{ml})$ was $9 \mathrm{mg}$.

dYield $(\%)=\left(\right.$ mass of removed $\left.\mathrm{CO}_{2} / 9\right) \times 100$

performance was comparable to those of amine-functionalized SBA-15 (>95\%), silver nanoparticle-conjugated mesoporous SBA-15 $(>95 \%)$, and magnetic particles $(>95 \%))^{4-9}$ In addition, this performance was much better than those of other enzymeencapsulated hydrogels. ${ }^{17-19}$ Next, its storage stability was examined by measuring the residual activity after storing the gel at $30^{\circ} \mathrm{C}$ for 35 days (Figure 6b). No reduced activity in the dc-ngCA-silk hydrogel was observed during this period, which implied that the encapsulated $n g \mathrm{CA}$ was not released from the silk hydrogel. However, free $n g \mathrm{CA}$ showed $\sim 11 \%$ of its initial activity after 10 days of incubation at $30^{\circ} \mathrm{C}$ (Supplementary Figures S5), and the sc-ngCA-silk hydrogel was completely degraded within 7 days (Supplementary Figures S6). The outstanding storage stability of the dc-ngCA-silk hydrogel seems to be due to the strong structural stability and high melting temperature $\left(\sim 400^{\circ} \mathrm{C}\right)$ of $\beta$-pleated-sheet crystals. ${ }^{61}$ This performance also surpassed the performance of other supports as mentioned above. ${ }^{4,6-9}$ Considering that the mineral carbonation process in which $\mathrm{CO}_{2}$ is converted into calcium carbonate $\left(\mathrm{CaCO}_{3}\right)$ can be performed at $30^{\circ} \mathrm{C},{ }^{62}$ the dc-ngCA-silk hydrogel could be used as a biocatalyst during a long operational period for the conversion process. Finally, the thermal stability of the dc-ngCA-silk hydrogel was evaluated after incubation at $50^{\circ} \mathrm{C}$. The dc-ngCA-silk hydrogel exhibited $\sim 91$ and $\sim 41 \%$ of its initial activity after $1 \mathrm{~h}$ and $12 \mathrm{~h}$, respectively (Figure $6 \mathrm{c}$ ), which was comparable to the levels of amine-based silica and exceeded those of amine-functionalized SBA- $15 .{ }^{4,8}$ In contrast, the activity of the free enzyme decreased to $\sim 4 \%$ within $1 \mathrm{~h}$ (Figure $6 \mathrm{c}$ ). The high thermal stability of the dc-ngCA-silk hydrogel appears to be due to its excellent structural stability, inevitably restricting the molecular flexibility of $n g C A .{ }^{49}$ Collectively, the high multi-use stability, outstanding storage stability and good thermal stability of the dc-ngCA-silk hydrogel may be due to the strong retention and excellent stability of the encapsulated $n g C A$ and the remarkable structural stability of the dual-crosslinked silk hydrogel.

\section{$\mathrm{CO}_{2}$ sequestration into $\mathrm{CaCO}_{3}$ using the dc-ngCA-Silk hydrogel}

The capability of the dc-ngCA-silk hydrogel to sequestrate $\mathrm{CO}_{2}$ was evaluated by measuring the amount of $\mathrm{CO}_{2}$ that was converted into $\mathrm{CaCO}_{3}$ when using the hydrogel for a certain period of time. The formation of $\mathrm{CaCO}_{3}$ might only be affected by the hydration of $\mathrm{CO}_{2}$ (that is, the concentration of bicarbonate $\left(\mathrm{HCO}_{3}{ }^{-}\right)$) under a sufficient quantity of $\mathrm{Ca}^{2+}$ and saturated amounts of $\mathrm{CO}_{2}$ dissolved in distilled water, which means that the gas-liquid mass transfer of $\mathrm{CO}_{2}$ was not rate determining in this closed system. We estimated the mass of removed $\mathrm{CO}_{2}$ from the precipitated $\mathrm{CaCO}_{3}$. The dc-ngCA-silk hydrogel exhibited $\sim 60 \%$ of the $\mathrm{CO}_{2}$ hydration activity of free $n g \mathrm{CA}$ enzyme (Figure $7 \mathrm{a}$ and Table 2 ), which coincided with the $p$-NPA hydrolysis activity (Figure 2b) and was comparable to that of $n g \mathrm{CA}$ encapsulated in R5 peptide-based bioinspired silica. ${ }^{5}$ Owing to this high activity, dc-ngCA-silk hydrogel hydrated an approximately twofold greater quantity of $\mathrm{CO}_{2}(\sim 2.4 \mathrm{mg}, \sim 26 \%$ of the total amount of $\left.\mathrm{CO}_{2}\right)$ than a non-catalyzed reaction $(\sim 1.3 \mathrm{mg}, \sim 13 \%$ of total amount of $\mathrm{CO}_{2}$ ) (Table 2). The morphology and polymorphs of $\mathrm{CaCO}_{3}$ precipitated by the dc-ngCA-silk hydrogel were also analyzed (Figures $7 \mathrm{~b}$ and c). The crystal structure of the precipitated $\mathrm{CaCO}_{3}$ was mainly composed of spherical vaterite with a diameter of $2.5 \mu \mathrm{m}$, which was structurally identical to $\mathrm{CaCO}_{3}$ precipitated in the absence of a catalyst. The vaterite formation seemed to be due to decreased vaterite solubility at $\sim \mathrm{pH} 9.5\{$ Sheng Han, $2006 \# 66\} .{ }^{63}$ However, the conversion process of aqueous $\mathrm{CO}_{2}$ into $\mathrm{CaCO}_{3}$ was too brief to provide sufficient time to examine the effect of silk fibroin on $\mathrm{CaCO}_{3}$ crystallization. Therefore, the effects of the dc-ngCA-silk hydrogel on the morphology and polymorphs of $\mathrm{CaCO}_{3}$ were investigated using the ammonium carbonate vaporization method (Supplementary Figures S7). Standard rhombohedra of calcites formed on the surface of the dc-ngCA-silk hydrogel. This formation seemed to occur due to a high concentration of silk fibroin $(10 \% \mathrm{w} / \mathrm{v}){ }^{42,43}$ Overall, we concluded that the dc-ngCA-silk hydrogel could be successfully used as an efficient biocatalyst to sequestrate $\mathrm{CO}_{2}$ into carbonate minerals.

\section{CONCLUSIONS}

In the present study, we developed a tough, resilient, and stable CA-encapsulating protein hydrogel as a robust biocatalyst for $\mathrm{CO}_{2}$ sequestration. Through a bioinspired and rapid dual-crosslinking strategy, the CA enzyme was efficiently encapsulated within the silk hydrogel, and the encapsulated CA retained $\sim 60 \%$ of the activity of free CA. The mechanical properties of the dual-crosslinked CA-encapsulating silk hydrogel were remarkable, with high elasticity and flexibility, compressive moduli of $\sim 1.3 \mathrm{MPa}$ at $20 \%$ strain and $\sim 11 \mathrm{MPa}$ at $40 \%$ strain, and constant compression strength with an energy dissipation of $\sim 5 \mathrm{~kJ} \mathrm{~m}^{-3}$ at $20 \%$ strain over 20 cycles. In addition to good thermal stability, the dual-crosslinked CA-encapsulating silk hydrogel exhibited outstanding multi-use stability with $\sim 97 \%$ of its initial activity remaining after the sixth use. The silk hydrogel also had excellent storage and structural stabilities, exhibiting no deformation or reduction in activity after storage at $30{ }^{\circ} \mathrm{C}$ for 35 days. We also demonstrated the ability of the dual-crosslinked CA-encapsulating silk hydrogel to sequestrate $\mathrm{CO}_{2}$ into carbonate minerals with $\sim 60 \%$ of the $\mathrm{CO}_{2}$ hydration ability of the free enzyme, which was expected to be the maximal ability of the encapsulated CA. Thus, this highly tough and stable silk hydrogel fabricated through bioinspired dual-crosslinks demonstrated the general applicability of a silk hydrogel as a protective reaction matrix for a biocatalyst and, in particular, the successful use of this hydrogel as a biocatalyst for environmental-friendly $\mathrm{CO}_{2}$ sequestration.

\section{CONFLICT OF INTEREST}

The authors declare no conflict of interest.

\section{ACKNOWLEDGEMENTS}

This work was supported by the Energy Efficiency \& Resources Core Technology Program (20142020200980) of the Korea Institute of Energy Technology Evaluation and Planning grant funded by the Ministry of Trade, Industry and Energy, Korea (to HJ Cha), a Marine Biomaterials Research Center grant from the Marine Biotechnology Program of the Korea Institute of Marine Science \& Technology Promotion funded by the Ministry of Oceans and Fisheries, Korea (to HJ Cha and CS Kim), and the Basic Science Research 
Program (2016R1D1A3B03933824) of the National Research Foundation funded by the Ministry of Education, Korea (to CS Kim).

Author contributions: CSK, YJY and HJC designed the experiments. CSK, YJY, SYB performed the experiments and analyzed the data. CSK, YJY and HJC wrote the manuscript. HJC is the principal investigator.

1 Kim, I. G., Jo, B. H., Kang, D. G., Kim, C. S., Choi, Y. S. \& Cha, H. J. Biomineralizationbased conversion of carbon dioxide to calcium carbonate using recombinant carbonic anhydrase. Chemosphere 87, 1091-1096 (2012).

2 Barbero, R., Carnelli, L., Simon, A., Kao, A., Monforte, A. D., Ricco, M., Bianchi, D. \& Belcher, A. Engineered yeast for enhanced $\mathrm{CO}_{2}$ mineralization. Energ. Environ. Sci. 6, 660-674 (2013).

3 Savile, C. K. \& Lalonde, J. J. Biotechnology for the acceleration of carbon dioxide capture and sequestration. Curr. Opin. Biotechnol. 22, 818-823 (2011).

4 Forsyth, C., Yip, T. W.S. \& Patwardhan, S. V. $\mathrm{CO}_{2}$ sequestration by enzyme immobilized onto bioinspired silica. Chem. Commun. 49, 3191-3193 (2013).

5 Jo, B. H., Seo, J. H., Yang, Y. J., Baek, K., Choi, Y. S., Pack, S. P., Oh, S. H. \& Cha, H. $\mathrm{J}$. Bioinspired silica nanocomposite with autoencapsulated carbonic anhydrase as a robust biocatalyst for $\mathrm{CO}_{2}$ sequestration. ACS Catal. 4, 4332-4340 (2014).

6 Wanjari, S., Prabhu, C., Yadav, R., Satyanarayana, T., Labhsetwar, N. \& Rayalu, S. Immobilization of carbonic anhydrase on chitosan beads for enhanced carbonation reaction. Process Biochem. 46, 1010-1018 (2011)

7 Vinoba, M., Bhagiyalakshmi, M., Jeong, S. K., Yoon, Y. I. \& Nam, S. C. Capture and sequestration of $\mathrm{CO}_{2}$ by human carbonic anhydrase covalently immobilized onto aminefunctionalized SBA-15. J. Phys. Chem. C 115, 20209-20216 (2011).

8 Vinoba, M., Bhagiyalakshmi, M., Jeong, S. K., Yoon, Y. I. \& Nam, S. C. Carbonic anhydrase conjugated to nanosilver immobilized onto mesoporous SBA-15 for sequestration of $\mathrm{CO}_{2}$. J. Mol. Catal. B-Enzym. 75, 60-67 (2012).

9 Vinoba, M., Bhagiyalakshmi, M., Jeong, S. K., Nam, S. C. \& Yoon, Y. Carbonic anhydrase immobilized on encapsulated magnetic nanoparticles for $\mathrm{CO}_{2}$ sequestration. Chem. Eur. J 18, 12028-12034 (2012).

10 Hwang, E. T., Gang, H., Chung, J. \& Gu, M. B. Carbonic anhydrase assisted calcium carbonate crystalline composites as a biocatalyst. Green Chem. 14, 2216-2220 (2012).

11 Zhang, S., Zhang, Z., Lu, Y., Rostam-Abadi, M. \& Jones, A. Activity and stability of immobilized carbonic anhydrase for promoting $\mathrm{CO}_{2}$ absorption into a carbonate solution for post-combustion $\mathrm{CO}_{2}$ capture. Bioresour. Technol. 102, 10194-10201 (2011).

12 Partlow, B. P., Hanna, C. W., Rnjak-Kovacina, J., Moreau, J. E., Applegate, M. B. Burke, K. A., Marelli, B., Mitropoulos, A. N., Omenetto, F. G. \& Kaplan, D. L. Highly tunable elastomeric silk materials. Adv. Funct. Mater. 24, 4615-4624 (2014).

13 Zhao, F., Ma, M. L. \& Xu, B. Molecular hydrogels of therapeutic agents. Chem. Soc. Rev. 38, 883-891 (2009).

14 Kiyonaka, S., Sada, K., Yoshimura, I., Shinkai, S., Kato, N. \& Hamachi, I. Semi-wet peptide/protein array using supramolecular hydrogel. Nat. Mater. 3, 58-64 (2004).

15 Blanchette, C. D., Knipe, J. M., Stolaroff, J. K., DeOtte, J. R., Oakdale, J. S., Maiti, A., Lenhardt, J. M., Sirajuddin, S., Rosenzweig, A. C. \& Baker, S. E. Printable enzyme-embedded materials for methane to methanol conversion. Nat. Commun. 7 11900 (2016).

16 Gröger, H., Capine, E., Barthuber, A. \& Vorlop, K.-D. Asymmetric synthesis of an $(R)$-cyanohydrin using enzymes entrapped in lens-shaped gels. Org. Lett. 3, 1969-1972 (2001).

17 Mao, Y. J., Su, T., Wu, Q., Liao, C. A. \& Wang, Q. G. Dual enzymatic formation of hybrid hydrogels with supramolecular-polymeric networks. Chem. Commun. 50, 14429-14432 (2014).

18 Elnashar, M. M.M., Yassin, M. A. \& Kahil, T. Novel thermally and mechanically stable hydrogel for enzyme immobilization of penicillin $\mathrm{G}$ acylase via covalent technique. J. Appl. Polym. Sci. 109, 4105-4111 (2008).

19 Wang, J. Y., Miao, X. M., Fengzhao, Q. Q., Ren, C. H., Yang, Z. M. \& Wang, L. Using a mild hydrogelation process to confer stable hybrid hydrogels for enzyme immobilization. RSC Adv. 3, 16739-16746 (2013).

20 Wei, Q., Xu, M., Liao, C., Wu, Q., Liu, M., Zhang, Y., Wu, C., Cheng, L. \& Wang, Q. Printable hybrid hydrogel by dual enzymatic polymerization with superactivity. Chem. Sci. 7, 2748-2752 (2016)

21 Betigeri, S. S. \& Neau, S. H. Immobilization of lipase using hydrophilic polymers in the form of hydrogel beads. Biomaterials 23, 3627-3636 (2002).

22 Kim, M., Chen, W. G., Kang, J. W., Glassman, M. J., Ribbeck, K. \& Olsen, B. D. Artificially engineered protein hydrogels adapted from the nucleoporin Nsp1 for selective biomolecular transport. Adv. Mater. 27, 4207-4212 (2015).

23 Malda, J., Visser, J., Melchels, F. P., Jungst, T., Hennink, W. E., Dhert, W. J.A., Groll, J. \& Hutmacher, D. W. 25th Anniversary article: engineering hydrogel for biofabrication. Adv. Mater. 25, 5011-5028 (2013).

24 Peppas, N. A., Hilt, J. Z., Khademhosseini, A. \& Langer, R. Hydrogels in biology and medicine: from molecular principles to bionanotechnology. Adv. Mater. 18, 1345-1360 (2006).

25 Kopecek, J. Polymer chemistry: swell gels. Nature 417, 388-391 (2002).

26 Wang, Q., Yang, Z., Zhang, X., Xiao, X., Chang, C. K. \& Xu, B. A supramolecularhydrogel-encapsulated hemin as an artificial enzyme to mimic peroxidase. Angew. Chem. Int. Ed. 46, 4285-4289 (2007).
27 Weisman, S., Trueman, H. E., Mudie, S. T., Church, J. S., Sutherland, T. D. \& Haritos, V. S. An unlikely silk: the composite material of green lacewing cocoons. Biomacromolecules 9, 3065-3069 (2008).

28 Zhang, Y., Zhao, P., Dong, Z., Wang, D., Guo, P., Guo, X., Song, Q., Zhang, W. \& Xia, Q. Comparative proteome analysis of multi-layer cocoon of the silkworm, Bombyx mori. PLOS ONE 10, e0123403 (2015)

29 Lu, Q., Wang, X., Hu, X., Cebe, P., Omenetto, F. \& Kaplan, D. L. Stabilization and release of enzymes from silk films. Macromol. Biosci. 10, 359-368 (2010).

30 Lu, S., Wang, X., Lu, Q., Hu, X., Uppal, N., Omenetto, F. G. \& Kaplan, D. L. Stabilization of enzymes in silk films. Biomacromolecules 10, 1032-1042 (2009).

31 Murphy, A. R. \& Kaplan, D. L. Biomedical applications of chemically-modified silk fibroin. J. Mater. Chem. 19, 6443-6450 (2009).

32 Sun, Y.-L., Li, Q., Sun, S.-.M, Huang, J-C, Zheng, B.-Y., Chen, Q.-D., Shao, Z-Z \& Sun, H.-B. Aqueous multiphoton lithography with multifunctional silk-centred bio-resists. Nat. Comm. 6, 8612-8621 (2015).

33 Zhou, C. Z., Confalonieri, F., Jacquet, M., Perasso, R., Li, Z. G. \& Janin, J. Silk fibroin: structural implications of a remarkable amino acid sequence. Proteins 44 , 119-122 (2001).

34 Elvin, C. M., Carr, A. G., Huson, M. G., Maxwell, J. M., Pearson, R. D., Vuocolo, T. Liyou, N. E., Wong, D. C.C., Merritt, D. J. \& Dixon, N. E. Synthesis and properties of crosslinked recombinant pro-resilin. Nature 437, 999-1002 (2005).

35 Tilley, K. A., Benjamin, R. E., Bagorogoza, K. E., Okot-Kotber, B. M., Prakash, 0. \& Kwen, $H$. Tyrosine cross-links: molecular basis of gluten structure and function. J. Agr. Food Chem. 49, 2627-2632 (2001).

36 Partlow, B. P., Hanna, C. W., Rnjak-Kovacina, J., Moreau, J. E., Applegate, M. B., Burke, K. A., Marelli, B., Mitropoulos, A. N., Omenetto, F. G. \& Kaplan, D. L. Highly tunable elastomeric silk biomaterials. Adv. Funct. Mater. 24, 4615-4624 (2014).

37 Das, S., Pati, F., Choi, Y. J., Rijal, G., Shim, J. H., Kim, S. W., Ray, A. R., Cho, D. W. \& Ghosh, S. Bioprintable, cell-laden silk fibroin-gelatin hydrogel supporting multilineage differentiation of stem cells for fabrication of three-dimensional tissue constructs. Acta Biomater. 11, 233-246 (2015).

38 Yang, Y. J., Kim, C. S., Choi, B. H. \& Cha, H. J. Mechanically durable and biologically favorable protein hydrogel based on elastic silklike protein derived from sea anemone. Biomacromolecules 16, 3819-3826 (2015).

39 Huang, S. H., Xue, Y. F., Sauer-Eriksson, E., Chirica, L., Lindskog, S. \& Jonsson, B. H. Crystal structure of carbonic anhydrase from Neisseria gonorrhoeae and its complex with the inhibitor acetazolamide. J. Mol. Biol. 283, 301-310 (1998).

40 Cheng, Y., Koh, L. D., Li, D. C., Ji, B. H., Han, M. Y. \& Zhang, Y. W. On the strength of $\beta$-sheet crystallites of Bombyx mori silk fibroin. J. R. Soc. Interface 11 2014 0305-20140312 (2014)

41 Luo, K., Yang, Y. \& Shao, Z. Physically crosslinked biocompatible silk-fibroin-based hydrogels with high mechanical performance. Adv. Funct. Mater. 26, 872-880 (2015).

42 Keene, E. C. Evans, J. S. \& Estroff, L. A. Silk fibroin hydrogels coupled with the $\mathrm{n} 16 \mathrm{n}-\beta$-chitin complex: An in vitro organic matrix for controlling calcium carbonate mineralization. Cryst. Growth Des. 10, 5169-5175 (2010).

43 Hao, W., Porter, D., Wang, X. T. \& Shao, Z. Z. Silk fibroin-mediated biomineralization of calcium carbonate at the air/water interface. CrystEngComm 16, 9176-9184 (2014).

44 Vepari, C. \& Kaplan, D. L. Silk as a biomaterial. Prog. Polym. Sci. 32, 991-1007 (2007).

45 Wells, J. W., Kandel, S. I., Kandel, M. \& Gornall, A. G. The esterase activity of bovine carbonic anhydrase B above $\mathrm{pH}$ 9. Reversible and cooalent inhibition by acetazolamide. J. Biol. Chem. 250, 3522-3530 (1975).

46 Bahn, S. Y., Jo, B. H., Hwang, B. H., Choi, Y. S. \& Cha, H. J. Role of Pif97 in nacre biomineralization: In vitro characterization of recombinant $P$ if97 as a framework protein for the association of organic-inorganic layers in nacre. Cryst. Growth Des. 15, 3666-3673 (2015)

47 Elleby, B., Sjoblom, B. \& Lindskog, S. Changing the efficiency and specificity of the esterase activity of human carbonic anhydrase II by site-specific mutagenesis. Eur. J. Biochem. 262, 516-521 (1999).

48 Secundo, F. Conformational changes of enzymes upon immobilisation. Chem. Soc. Rev. 42, 6250-6261 (2013).

49 Arnold, F. H., Wintrode, P. L., Miyazaki, K. \& Gershenson, A. How enzymes adapt: lessons from directed evolution. Trends Biochem. Sci. 26, 100-106 (2001).

50 Harms, G. S., Pauls, S. W., Hedstrom, J. F. \& Johnson, C. K. Fluorescence and rotational dynamics of dityrosine. J. Fluoresc. 7, 283-292 (1997).

$51 \mathrm{Hu}$, X., Kaplan, D. L. \& Cebe, P. Determining beta-sheet crystallinity in fibrous proteins by thermal analysis and infrared spectroscopy. Macromolecules 39, 6161-6170 (2006).

52 Guziewicz, N., Best, A., Perez-Ramirez, B. \& Kaplan, D. L. Lyophilized silk fibroin hydrogels for the sustained local delivery of therapeutic monoclonal antibodies. Biomaterials 32, 2642-2650 (2011).

53 Gil, E. S., Frankowski, D. J., Spontak, R. J. \& Hudson, S. M. Swelling behavior and morphological evolution of mixed gelatin/silk fibroin hydrogels. Biomacromolecules $\mathbf{6}$, 3079-3087 (2005).

54 Baker, M. I., Walsh, S. P., Schwartz, Z. \& Boyan, B. D. A review of polyvinyl alcohol and its uses in cartilage and orthopedic applications. J. Biomed. Mater. Res. B 100, 1451-1457 (2012).

55 Delalleau, A., Josse, G., Lagarde, J.-M., Zahouani, H. \& Bergheau, J.-M. Characterization of the mechanical properties of skin by inverse analysis combined with the indentation test. J. Biomech. 39, 1603-1610 (2006). 
56 Pini, M., Wiskott, H. W.A., Scherrer, S. S., Botsis, J. \& Belser, U. C. Mechanical characterization of bovine periodontal ligament. J. Periodont. Res. 37, 237-244 (2002).

57 Li, J., Illeperuma, W. R.K., Suo, Z. \& Vlassak, J. J. Hybrid hydrogels with extremely high stiffness and toughness. ACS Macro. Lett. 3, 520-523 (2014).

58 Gong, J. P. Why are double network hydrogels so tough? Soft Matter 6, 2583-2590 (2010).

59 Nakajima, T., Furukawa, H., Tanaka, Y., Kurokawa, T., Osada, Y. \& Gong, J. P. True chemical structure of double network hydrogels. Macromolecules 42, 2184-2189 (2009).

60 Harrass, K., Kruger, R., Moller, M., Albrecht, K. \& Groll, J. Mechanically strong hydrogels with reversible behaviour under cyclic compression with MPa loading. Soft Matter 9, 2869-2877 (2013).

61 Cebe, P., Hu, X., Kaplan, D. L., Zhuravlev, E., Wurm, A., Arbeiter, D. \& Schink, C. Beating the heat-fast scanning melts silk beta sheet crystals. Sci. Rep. 3, 1130 (2013).

62 Sanna, A., Hall, M. R. \& Maroto-Valer, M. Post-processing pathways in carbon capture and storage by mineral carbonation (CCSM) towards the introduction of carbon neutral materials. Energ. Environ. Sci. 5, 7781-7796 (2012).
63 Han, S. Y., Hadiko, G., Fuji, M. \& Takahashi, M. Crystallization and transformation of vaterite at controlled pH. J. Cryst. Growth 289, 269-274 (2006).

This work is licensed under a Creative Commons Attribution 4.0 International License. The images or other third party material in this article are included in the article's Creative Commons license, unless indicated otherwise in the credit line; if the material is not included under the Creative Commons license, users will need to obtain permission from the license holder to reproduce the material. To view a copy of this license, visit http:// creativecommons.org/licenses/by/4.0/

(C) The Author(s) 2017

Supplementary Information accompanies the paper on the NPG Asia Materials website (http://www.nature.com/am) 